\title{
Newcastle disease virus induces pro-inflammatory conditions and type $I$ interferon for counter-acting Treg activity
}

\author{
PHILIPPE FOURNIER $^{1}$, ANNETTE ARNOLD $^{1}$, HOLGER WILDEN $^{1}$ and VOLKER SCHIRRMACHER ${ }^{1,2}$ \\ ${ }^{1}$ German Cancer Research Center, Im Neuenheimer Feld 280, D-69120 Heidelberg; ${ }^{2}$ Center of Immunology \\ and Oncology (IOZK), Hohenstaufenring 30-32, D-50674 Köln, Germany
}

Received August 16, 2011; Accepted October 4, 2011

DOI: 10.3892/ijo.2011.1265

\begin{abstract}
Newcastle disease virus (NDV) is a negative sense RNA paramyxovirus of birds which in human tumor cells, in contrast to human non-tumor cells, has shown replication competence leading to tumor cell death (i.e., tumor selectivity and viral oncolysis). Our study demonstrates that this virus induces high levels of pro-inflammatory cytokines in the bronchial lavage fluid of mice after nasal application and also in vitro in human dendritic cells (DCs). NDV is known as a very efficient inductor of type I interferon (IFN). The presented data show the key role played by the cell surface receptor to type I IFN (IFNAR) but not by the interferon transcription factors IRF-3 and IRF-7 in the induction of the important pro-inflammatory cytokine IL-12 upon transcription of NDV genes in DCs. We show that NDV activates in infected cells the helicase RIG-I. In Tregs, the activation of RIG-I was shown in other studies to inhibit the suppressive function of these cells. We thus conclude that NDV in tumor therapy may help to stimulate $\mathrm{T}$ effector cells but also to block Treg cells, thereby alleviating a brake to antitumor activity.
\end{abstract}

\section{Introduction}

Dendritic cells (DCs) are professional antigen-presenting cells (APCs) which are characterized by a unique ability to stimulate the proliferation of $\mathrm{T}$ cells and by their functional plasticity in the induction of distinct $\mathrm{T}$ helper responses to the encountered stimulus $(1,2)$. Recent developments in the ex vivo generation of monocyte-derived DCs (MDDCs) (3) enable to obtain a large number of DCs to be used as professional APCs for treating tumors. However, despite encouraging results in initial cancerbased clinical investigations (4,5), DC-mediated immunotherapy does not aways induce sufficient acquired immunity to lead to

Correspondence to: Professor Volker Schirrmacher, German Cancer Research Center (DKFZ), Im Neuenheimer Feld 280, D-69120 Heidelberg, Germany

E-mail: v.schirrmacher@dkfz.de

Key words: Newcastle disease virus, anti-tumor immunity, Treg, virus replication, viral transcription, dendritic cells, RIG-I, type I interferon, IL-6, IL-12, IL-10, IRF-3, IRF-7, IFNAR tumor regression $(4,6)$. This might be due to tumor mass which can cause various adverse effects to an immune response, including the problem of regulatory $\mathrm{T}$ cells (Tregs). Such cells accumulate in human tumors and in the peripheral blood of patients with cancer (7). Tregs contribute to the creation of an immunosuppressive environment which favors suppression of anti-tumor immune responses and down-regulation of immune activity of effector $\mathrm{T}$ cells (Teffs) by a variety of mechanisms including for example IL-10 and TGF- $\beta 1$ production (8). This is in particular true for immature DCs which can be observed at the tumor site. They can ingest and process antigen, but are tolerogenic for $\mathrm{T}$ cell responses $(9,10)$. For a productive $\mathrm{T}$ cell response, they must become mature DCs, expressing high levels of $\mathrm{MHC}$ and co-stimulatory molecules, such as CD40, CD80, CD83, and CD86 $(9,11,12)$. Danger signals, such as pathogen-associated molecular patterns derived from microbes, viral components, or pro-inflammatory cytokines, can provide immature DCs with maturation signals via TLRs (13), RIG-I-like sensors in the cytosol (11), or cytokine receptors. Such signals make DCs capable of priming Ag-specific T cells $(9,10,14)$. Viruses are recognized by the innate immune system through various host pattern-recognition receptors $(12,15)$ to stimulate the immune system and induce CTL activity (16), even in a context of strong immunosuppression. Oncolytic viruses as new cancer therapeutics are non-pathogenic, naturally occurring RNA or DNA viruses. Oncolytic RNA viruses have received considerable attention recently as virotherapy agents and as oncolytic viral therapeutics (17), since they do not integrate into DNA and have a high safety profile. Several cytosolic receptors have recently been described to recognize molecular patterns present within viral RNA. The retinoic acid-inducible gene I (RIG-I)-like helicase family (18) including RIG-I, melanoma differentiation-associated gene 5 (MDA-5) and LGP2 are cytosolic RNA sensors of RNA viruses. Their activation leads to type I IFN responses (19-21). Newcastle disease virus (NDV) is a negative sense RNA virus with oncolytic activity which has the longest history in the clinic (23). Its selective replication in tumor cells has been shown to be due to lack of proper antiviral responses in tumor cells $(24,25)$. NDV strains are divided into three pathotypes: highly virulent (velogenic) strains that cause severe respiratory and neurologic diseases in chickens; moderately virulent (mesogenic) strains that cause milder disease in chicken, and non-pathogenic (lentogenic) strains that cause inapparent infections in birds. Both mesogenic (e.g., MTH-68) and lentogenic (e.g., LaSota or Ulster) strains 
have been used for virotherapy of tumors. Induction of type I interferon (IFN) and of pro-inflammatory cytokines represents the first line of host defense against viruses (26). NDV is known as a potent inducer of both alpha and beta interferon (IFN- $\alpha / \beta)$ production and of dendritic cell maturation. Although virtually any cell can produce IFN- $\alpha / \beta$ in response to viral pathogens, plasmacytoid dendritic cells (pDCs) are the strongest IFN- $\alpha / \beta$ producers in the body (27). IFN- $\alpha / \beta$ mediates signals through a common cell surface receptor, the type I IFN receptor (IFNAR), leading to the transcription of hundreds to thousands of genes. Some of the induced proteins increase the resistance of cells to infection by directly inhibiting viral replication. In addition IFNs up-regulate the expression of MHC class I molecules and activate NK cells which preferentially kill cells with a low MHC class I level. Therefore, IFNs protect uninfected cells from NK cells by increasing the expression of MHC class I molecules, while infected cells are killed either by the better antigen presentation to $\mathrm{T}$ cells or by the activated NK cells. The anti-tumor activities and immunostimulatory properties of this virus have long been recognized. Therefore, this agent has been used for several decades in cancer patients. Replication-competent oncolytic NDV has been developed for cancer therapy (28). Reverse genetics technology has recently enabled the construction of recombinant NDV particles (29) with incorporated foreign therapeutic genes. Such replication-competent viral vectors appear to be well suited for cancer gene therapy because NDV replicates efficiently in tumor cells leading to the expression in the infected cells of the transgene which is inserted within the viral genome [for example: interleukin (IL)-2 $(30,31)$ or GM-CSF (32)]. Cytokines released by APCs govern the differentiation pathway of cognate interacting $\mathrm{T}$ cells. For example, the production of the cytokine IL-12 is indispensable for mounting T helper type 1 (TH1) responses by inducing the production of interferon- $\gamma$ (IFN- $\gamma)(33,34)$. In contrast, IL-10, which is induced notably by interferon- $\alpha$, is an anti-inflammatory cytokine. This cytokine is produced primarily by monocytes and to a lesser extent by lymphocytes. IL-10 has pleiotropic effects in immunoregulation and inflammation. It down-regulates the expression of Th1 cytokines, MHC class II antigens, and co-stimulatory molecules on macrophages. As such it contributes to counteracting excessive immunity in the body. We demonstrated previously (35) that NDV can be used for immune activation of human DCs. Infection with NDV of in vitro generated human DC leads to expression of viral M and RIG-I gene transcripts which are increased upon co-stimulation with LPS. An optimal combination of NDV and LPS leads to the polarization of DCs to DC1 type cytokines with a high ratio of interleukin IL-12 to IL-10 (35).

In this study, we show that NDV induces pro-inflammatory cytokines in vivo after intranasal application in mice and in vitro in MDDCs. Interferon- $\alpha$ was also induced in human DC upon NDV addition but the production of IL-12 by these cells was found to necessitate an additional co-stimulation signal provided by bacterial LPS. The maturation of mouse bone marrow derived DCs (BM-DCs) with LPS was linked with a stronger viral transcription in these cells associated with a lower interferon response. With UV-light inactivated NDV, the interferon response of BM-DCs was reduced, confirming the association between the NDV transcription events and the induction of these responses. Deletion of genes of the type I IFN response were found to lead to higher viral transcription associated with lower cell viability. In particular, deletion of the interferon regulatory factor (IRF)-3 and -7 coding genes led to reduced type I IFN- $\alpha$ and $-\beta$ responses. The strongest effect had the deletion of the IFNAR gene which blocked IFN- $\alpha$ and IL-12 production. The data encourage the use of NDV-based viral vectors as novel and powerful gene transfer modality for cytoplasmic gene expression in dendritic cells to overcome immunosuppression in cancer patients.

\section{Materials and methods}

Mice and cells. All the mouse strains had a C57BL/6 background. Wild-type mice were purchased from Charles River Laboratories (Sulzfeld, Germany). The IRF-3, IRF-7 and double knock-out mice were kindly provided by Dr A. Krug (Institute for Medical Microbiology, Immunology and Hygiene, Technical University Munich, Germany). The IFNAR ${ }^{-/-}$mice were kindly given by Dr R. Zawatsky (Division of Viral Transformation Mechanisms, German Cancer Research Center (DKFZ), Heidelberg, Germany). Animal studies were approved by the local regulatory agency (Regierung von Baden-Wüttemberg, Karlsruhe, Germany). Murine BM-DCs were generated as described in ref. 25). Human MDDCs were generated as previously described (35). Briefly, these cells were obtained by a culture of monocytes (which were derived from buffy coat) for 6 or 7 days at $5 \times 10^{5} / \mathrm{ml}$ in X-vivo ${ }^{\mathrm{TM}} 15$ medium (Cambrex, East Rutherford, NJ, USA) supplemented with $2 \%$ heat-inactivated HLA-A2 serum (Lonza, Cologne, Germany), $500 \mathrm{U} / \mathrm{ml}$ human GM-CSF, and $250 \mathrm{U} / \mathrm{ml}$ human IL-4 (both from PeproTech, London, UK). Half of the medium was replaced on day 3 or 4. Over $90 \%$ of cells were $\mathrm{CD}_{11 \mathrm{c}^{+}}$and essentially negative for CD3, CD56, CD19, and CD14 (all <1\%). The MDDCs exhibited an almost immature phenotype $\left(\mathrm{CD} 80^{+/}, \mathrm{CD} 86^{\text {low }}, \mathrm{HLA}^{\mathrm{D}} \mathrm{DR}^{\text {low }}\right.$, and $\mathrm{CD}^{\circ} 3^{\circ}$ ) and morphologically had short dendrites. Viable nucleated cells were counted using a standard trypan blue dye exclusion system.

Viruses and infections. Lentogenic NDV Ulster 2C (named NDV Ulster in this study) was obtained in 1984 from Dr P.H. Russel [Department of Microbiology and Parasitology, Royal Veterinary College, University of London (UK)]. Recombinant NDV expressing expressing the jellyfish enhanced green fluorescent protein (EGFP), named NDFL-EGFP, was generated from a cDNA clone of the lentogenic NDV strain LaSota as described (36) and was kindly provided by Dr B. Peeters (Division of Infectious Diseases, Animal Sciences Group, Wageningen UR, AB Lelystad, The Netherlands). NDV $M T H-68 / H$ (named NDV $M T H-68$ in this study) was kindly provided by Dr G. Noss (Malsch, Germany). All NDV viruses were propagated in embryonated chicken eggs, harvested from the allantoic fluid, purified by ultracentrifugation and characterized as described (37). Quantification was performed by hemagglutination (HA) assay. The smallest virus concentration leading to visible agglutination of sheep erythrocytes is defined as 1 HA unit (HU). NDV was UV inactivated for some experiments as described (37). Sendai virus was obtained from the animal facilities of the German Cancer Research Center (DKFZ). For infection, 5x10 DC were incubated at a defined MOI in $100 \mu \mathrm{l}$ medium without serum per well of 24-well flat bottom plates for $4 \mathrm{~h}$ before the addition of $1000 \mu \mathrm{l}$ culture medium supplemented with serum 
(10\% FCS in case of mouse BM-DCs, $2 \%$ HLA-A2 serum in case of human MDDCs) for the indicated time.

Nasal immunization. Mice were anaesthetized by isofluorane and inoculated intranasally with $100 \mu 1$ of purified MTH-68 virus containing $1000 \mathrm{HA} \mathrm{U} / \mathrm{ml}$. A group of 3 mice was mock infected with PBS containing 0.2\% EDTA (PBS/EDTA). Mice were weighed and examined two times daily for clinical signs, change in activity and behavior. Three mice from each group were euthanized at 1 and 2 day(s) post inoculation by $\mathrm{CO}_{2}$ asphyxiation. Immediately post mortem, lungs were washed using $1.0 \mathrm{ml}$ of ice cold $0.9 \% \mathrm{NaCl}$. Red blood cells were lysed using ACK lysing buffer $\left(0.15 \mathrm{M}, 1 \mathrm{mM} \mathrm{KHCO}{ }_{3}, 0.1\right.$ mM EDTA). Differential cell counts were obtained manually under light microscopy. The supernatant was kept at $-80^{\circ} \mathrm{C}$ until assessed for cytokine content.

Antibodies and flow cytometry. The abundance of CD80 on the surface of human MDDCs $\left(\mathrm{CD}_{\left.11 \mathrm{c}^{+}\right)}\right)$was analyzed by a FACSCalibur with a fluorescein isothiocyanate-conjugated antibody against CD80 and a PE-conjugated antiCD11c mAb (both from BD Biosciences, Heidelberg, Germany) as previously described in detail (35). EGFP signal in mouse BM-DCs was measured as FL-1 signal. All experiments were performed using a FACScan flow cytometer (Becton-Dickinson, Heidelberg, Germany) and the FACS data were analyzed with the WinMDI 2.8 software (Joe Trotter, The Scripps Research Institute, CA, USA).

RNA isolation, $c D N A$ preparation and real-time quantitative polymerase chain reaction $(q P C R)$. Cells were washed in PBS and cell pellets were either shock-frozen in liquid nitrogen for storage at $-80^{\circ} \mathrm{C}$ or immediately used for RNA isolation. Cells were disrupted using a rotor-stator homogeniser. Total RNA was extracted using the RNeasy mini kit (Qiagen, Hilden, Germany) according to the manufacturer's instructions. Total RNA was then reversely transcribed into cDNA using Oligo(dT)12-18 primers and the SuperScript ${ }^{\mathrm{TM}}$ II Reverse Transcriptase (both Invitrogen, Karlsruhe, Germany) according to the manufacturer's instructions. For the real-time PCR, primers, which bound just once in the genome when tested in a database search (BLAST, NCBI), were designed. The primers were optimized to show a melting curve with one peak only and to have approximately the same amplification efficiency as the gene used for normalization. The master mix was prepared as recommended by the manufacturer (Eurogentec, Seraing, Belgium) and the concentrations for the primers and for $\mathrm{MgCl}_{2}$ were adjusted. Quantitative PCR was carried out using a Gene Amp ${ }^{\circledR} 5700$ Sequence Detection System (Applied Biosystems, Weiterstadt, Germany). After an initial incubation of $25 \mu \mathrm{l}$ reaction mix (Eurogentec, Seraing, Belgium) for $10 \mathrm{~min}$ at $95^{\circ} \mathrm{C}$, amplification was performed for 45 cycles consisting of a $15 \mathrm{sec}$ hold at $95^{\circ} \mathrm{C}$ and a 1 min hold at $60^{\circ} \mathrm{C}$. The expression of the target genes was normalized with the respective housekeeping gene after it had been ensured that the amplification efficiency was the same. For the viral $\mathrm{M}$ gene and $\beta$-actin detection, a fluorescent oligonucleotide probe system was used, while the other genes (mouse: IRF-7, IRF-3 and RIG-I) were detected with SYBR green. The sequences of the primers and the probes were previously described (25).
Detection of cytokines. Levels of IL-6, IL-10, MCP-1, TNF- $\alpha$, IL-12p70, IFN- $\gamma$ in the mouse bronchoalveolar lavages (BAL) were measured in undiluted, 1:10 and 1:100 diluted BAL fluid by Cytometric Bead Array and were analyzed with FCAP Array Software on the FACSArray (BD Biosciences, Heidelberg, Germany). Lower limits of detection for IL-6, IL-10, MCP-1, IFN- $\gamma$, TNF- $\alpha$, IL- 12 p70 were $5,17.5,52.7,2.5,7.3$ and $10.7 \mathrm{pg} /$ $\mathrm{ml}$, respectively. Mouse IFN- $\alpha$ in supernatants of cultured cells was determined with ELISA using a rat monoclonal antibody and a rabbit polyclonal antibody against murine IFN- $\alpha$ (PBL Interferon Source, NJ, USA). Mouse IFN- $\beta$ was measured by ELISA using a rat monoclonal antibody specific for murine IFN- $\beta$ (United States Biological, MA, USA) and a rabbit polyclonal antibody against murine IFN- $\beta$ (PBL Interferon Source, NJ, USA). For the determination of both proteins, peroxidaseconjugated donkey anti-rabbit $\operatorname{IgG}(\mathrm{H}+\mathrm{L}) \mathrm{F}\left(\mathrm{ab}^{\prime}\right)_{2}$ fragment (Jackson ImmunoResearch Laboratories, PA, USA) was added to the well before adding the TMB substrate (Thermo Scientific Pierce, Bonn, Germany). Mouse IL-6, TNF- $\alpha$ and IL-12 cytokine concentrations were determined by ELISA (BD OptEIA, BD Biosciences). The amount of human IFN- $\alpha$, IL-12p70 and IL-10 in culture supernatants was measured by DuoSet ELISA development kit (R\&D Systems, Wiesbaden-Nordenstadt, Germany) according to the manufacturer's instructions.

MTS assay. The CellTiter $96^{\circledR}$ AQueous Non-Radioactive Cell Proliferation Assay (Promega, Mannheim, Germany) is a homogeneous, colorimetric method for determining the number of viable cells. The reagent is composed of solutions of a novel tetrazolium compound [3-(4,5-dimethylthiazol-2-yl)5-(3-carboxymethoxyphenyl)-2-(4-sulfophenyl)-2H-tetrazolium, inner salt, MTS] and an electron coupling reagent (phenazine methosulfate) PMS. MTS is bioreduced by cells into a formazan product that is soluble in tissue culture medium. The conversion of MTS into the aqueous soluble formazan product is accomplished by dehydrogenase enzymes found in metabolically active cells. The quantity of formazan product as measured by the amount of $490 \mathrm{~nm}$ absorbance is directly proportional to the number of living cells. After incubation at $37^{\circ} \mathrm{C}$ for 4 days of the DCs $\left(5 \times 10^{5}\right.$ cells per well in a 24 -well plate) with the different viruses to test, the plates are developed with the MTS reagent. The optical density at $490 \mathrm{~nm}$ is then measured using an ELISA reader. The percentage of inhibition of DCs' viability is determined using the following calculation: 1- [(A490 experimental well - A490 background)/(A490 positive control - A490 background)] x 100 using as control DC without addition of NDV and as background wells without DC.

Statistical analyses. All analyses were done with the GraphPad Prism 4.0 software (GraphPad Software, San Diego, CA, USA). P-values were calculated with a two-sided Student's t-test.

\section{Results}

Intranasal application of oncolytic NDV induces pro-inflammatory cytokines in mouse lung epithelial cells. The natural route of infection of birds by NDV goes via inhalation through the lung. To investigate the types of cytokines produced upon intranasal administration of NDV in a xenogenic animal model, we applied the MTH-68 strain of NDV in 2 groups 


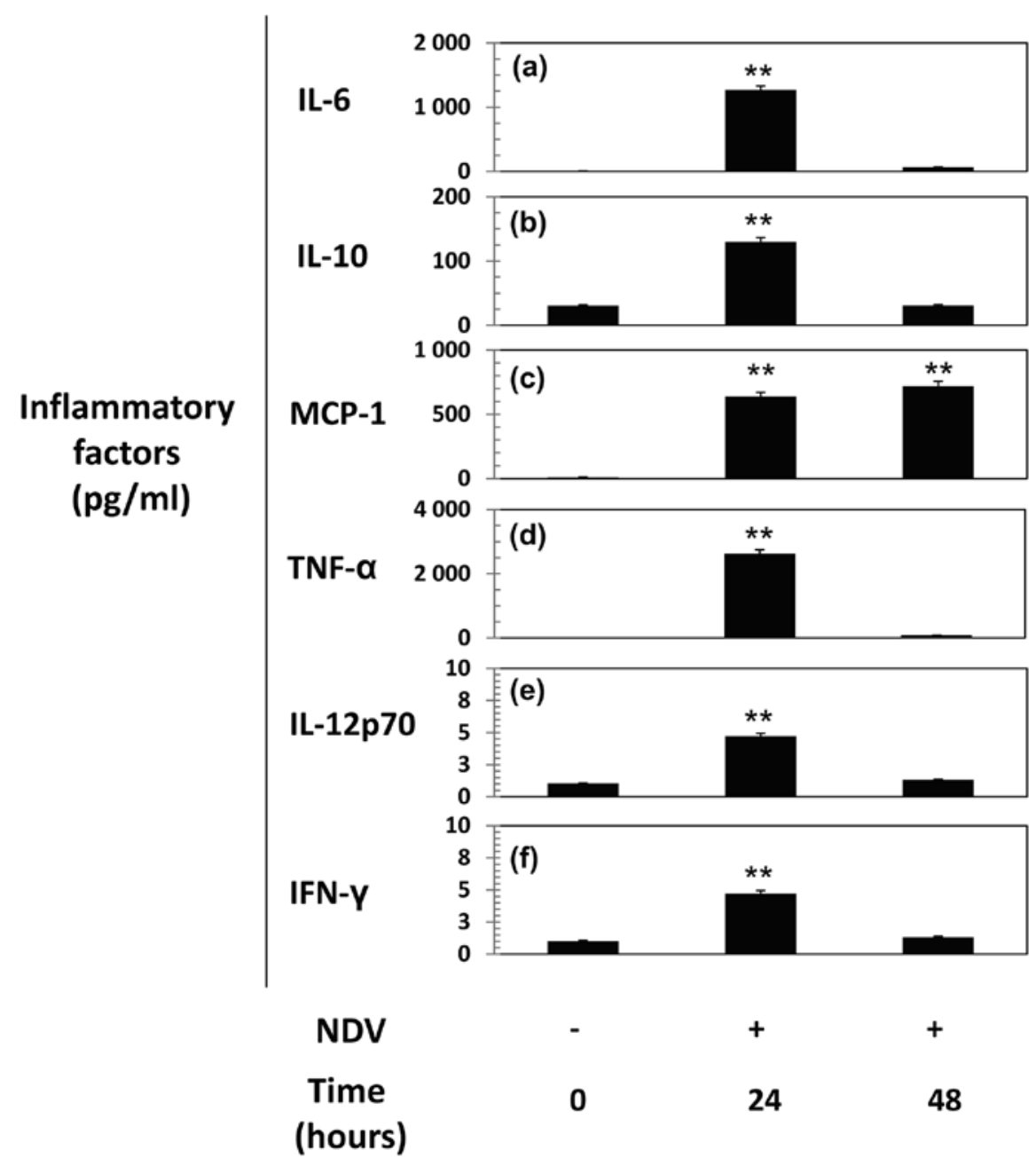

Figure 1. Cytokines in the BAL supernatants after intranasal application of the MTH68 strain of NDV. Two groups of 3 C57B16 mice were applied intranasally with $40 \mu \mathrm{l}$ of the purified strain $M T H-68$ of NDV $(10,000 \mathrm{HU} / \mathrm{ml})$ and one group of 3 mice with PBS/EDTA. Bronchoalveolar lavage was obtained from each mouse 24 or $48 \mathrm{~h}$ after NDV application, treated with an erythrocyte lysing solution and centrifuged. The different inflammatory cytokines (IL-6, IL-10, MCP-1, TNF, IL-12p70 and IFN- $\gamma$ ) were measured by Cytometric Bead Array in each supernatant. Data are presented in pg/ml for each cytokine [IL-6 (a), IL-10 (b), MCP-1 (c), TNF (d), IL-12p70 (e) and IFN- $\gamma$ (f)] in pg/ml as mean \pm SD, $n=3$ values per group. ** $\mathrm{p}<0.01$ compared to the PBS group.

of 3 mice. PBS/EDTA was used as negative control in a third group of 3 mice. Bronchoalveolar lavages (BAL) were obtained 24 and $48 \mathrm{~h}$ later and they were tested for various cytokines (IL-6, IL-10, MCP-1, TNF- $\alpha$, IL-12p70, IFN- $\gamma$ ) using the Mouse Inflammation Kit as described in Materials and methods. Intranasal application of NDV in C57BL6 mice provoked high levels of pro-inflammatory cytokines (IL-6, IL-10, MCP-1, TNF- $\alpha$, IL-12p70, IFN- $\gamma$ ) (Fig. 1). These cytokines (except MCP-1) vanished quickly and were not present anymore $48 \mathrm{~h}$ post-administration.

Induction of cytokines by NDV in human MDDCs. Human MDDCs were given various doses (from 0.03 to $30 \mathrm{HU} / 10^{6}$ cells) of three different viruses (MTH-68 strain of NDV, Sendai Virus and Ulster strain of NDV). Supernatants were tested $24 \mathrm{~h}$ later for the presence of cytokines by ELISA. We observed IFN- $\alpha$ and IL-6 production in a dose-dependent fashion. MTH- 68 was in this respect a stronger inducer than the Ulster strain of NDV (Fig. 2A). Remarkable was the high variability in cellular responses between the 2 cell donors. To test whether LPS was required as supplementary costimulatory signal for cytokine production, we tested various combinations of the strain Ulster of NDV and LPS. Addition of LPS had no major influence on the production of IFN- $\alpha$ (Fig. 2Ba). However, LPS led to detectable IL-12 production upon NDV addition (Fig. 2Bb). The cytokine IL-10 was produced upon NDV addition ( $5 \mathrm{HU}$ and $25 \mathrm{HU} / 10^{6}$ cells), independently of the presence of LPS (Fig. 2Bc). Upon analysis by flow cytometry of $\mathrm{CD} 11 \mathrm{c}^{+}$cells, coexpression of CD80 revealed that LPS and NDV induced maturation of the MDDCs in a concentration-dependent manner. An optimal LPS concentration of $30 \mathrm{ng} / \mathrm{ml}$ allowed the best maturation of the MDDCs by NDV (Fig. 2Bd).

Induction of the type 1 interferon response in DC is linked to viral transcription. To examine whether LPS maturation alters viral replication and the interferon response in dendritic cells, mouse BM-DCs were prepared with or without a maturation step of 24-h treatment with LPS. The cells were then infected with NDFL-EGFP, a recombinant La Sota strain of NDV into which the EGFP gene has been inserted, as an internal fluorescence marker. As shown in Fig. 3Aa, flow cytometry analysis of the infected dendritic cells showed that LPS matured MDDCs 
A

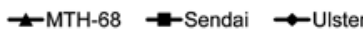

\section{Cytokines (pg/ml)}

Donor 1

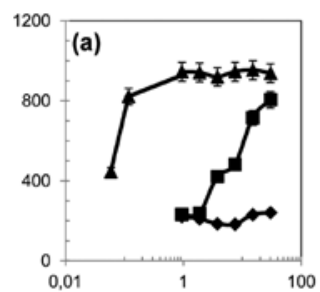

Donor 2
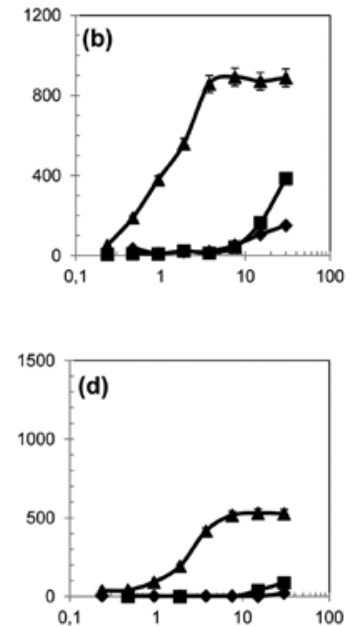

IFN- $\alpha$

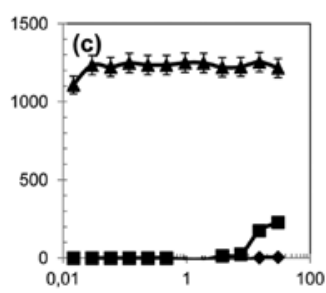

Virus (HU/ $\left.10^{6} \mathrm{DC}\right)$ expressed a brighter EGFP signal than not matured DCs. These observations were confirmed by quantitative PCR analysis of the relative amount of viral $M$ transcripts (Fig. 3Ab). We next quantified the level of transcripts of proteins belonging to the interferon response (Fig. 3B): IRF-7 (c), RIG-I (d) and

Figure 2. In vitro production of cytokines and expression of the CD80 marker in human MDDCs upon NDV addition. (A) In vitro induction of the IL-6 and IFN- $\alpha$ protein by Ulster $(\bullet), M T H-68$ (४) strains of NDV and by Sendai virus (๘). Human MDDCs, which were obtained from 2 different donors and generated via a 6 days culture in X-vivo ${ }^{\mathrm{TM}} 15$ medium supplemented with GM-CSF and IL-4, were plated in 24 -well plates $\left(5 \times 10^{5}\right.$ cells/well). Four hours later, 3 different viruses were given at various doses (indicated here in HU/ $10^{6} \mathrm{DC}$ ). Supernatants were taken after $24 \mathrm{~h}$ and assessed by ELISA for their content in IL-6 [(a) and (c) respectively for donors 1 and 2] and IFN- $\alpha$ [(b) and (d) respectively for donors 1 and 2]. (B) In vitro production of IFN- $\alpha$, IL-12 and IL-10 and expression of the CD11c and CD80 markers $10.5 \mathrm{~h}$ after co-addition of the Ulster strain of NDV and LPS. Human MDDCs were plated in 24-well plates at $5 \times 10^{5}$ cells/well. LPS and NDV Ulster were added in triplicates at different concentrations as indicated on the x-axis. The supernatants of each well were collected $24 \mathrm{~h}$ later and, after centrifugation, were assessed by ELISA for their contents in IFN- $\alpha$ (a), IL-12 (b) and IL-10 (c). The concentrations of the cytokines are indicated in $\mathrm{pg} / \mathrm{ml}$. The cells were resuspended by incubating the cells with PBS-EDTA $20 \mathrm{mM}$ and analyzed by flow cytometry after double staining with CD11c and CD80 specific mAbs which were coupled to fluorochrome as indicated in Materials and methods. The diagram (d) represents the percentage of $\mathrm{CD} 11 \mathrm{c}^{+} \mathrm{CD} 80^{+}$cells for the different conditions of LPS and NDV tested.

\section{B}

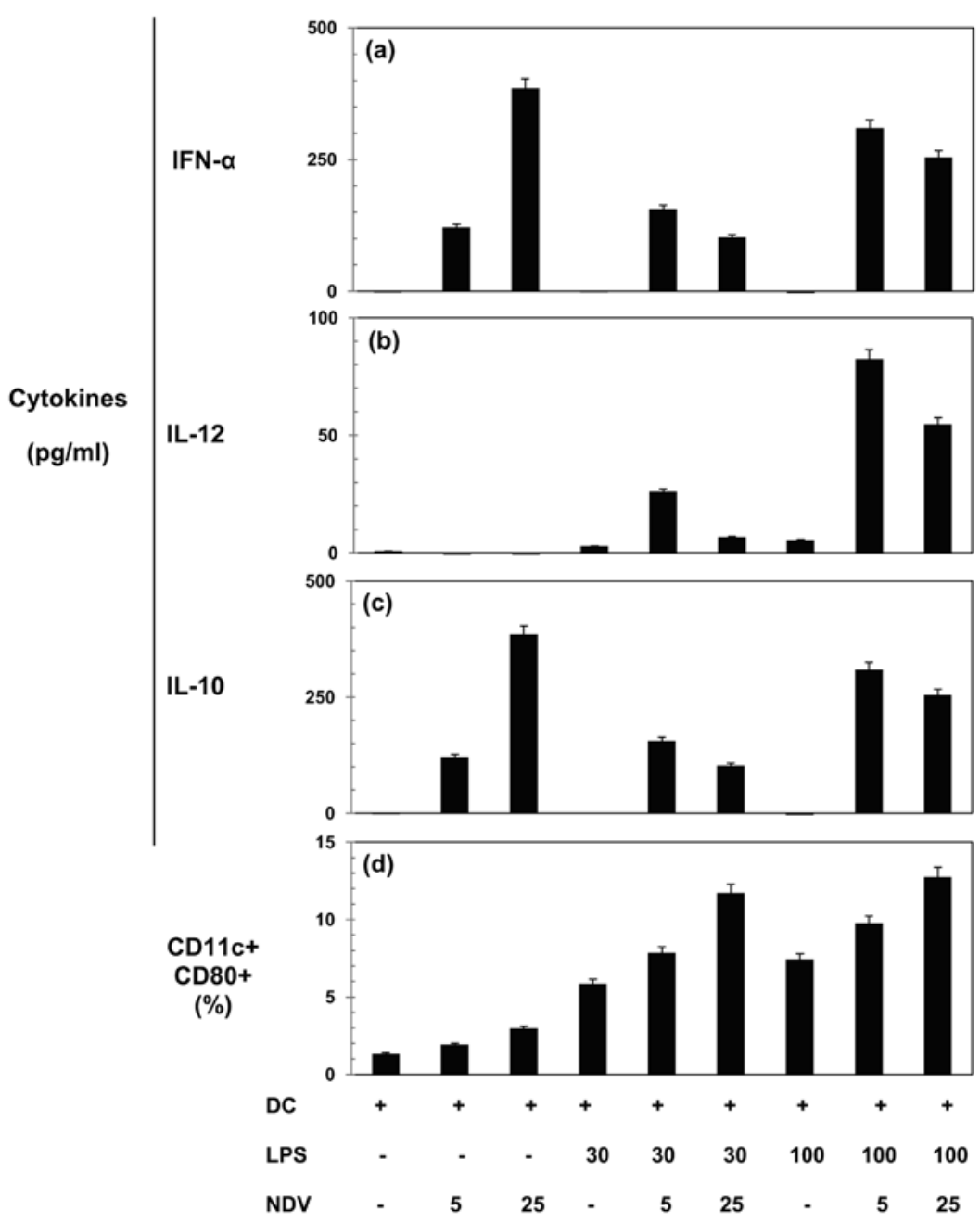


A)

Viral replication
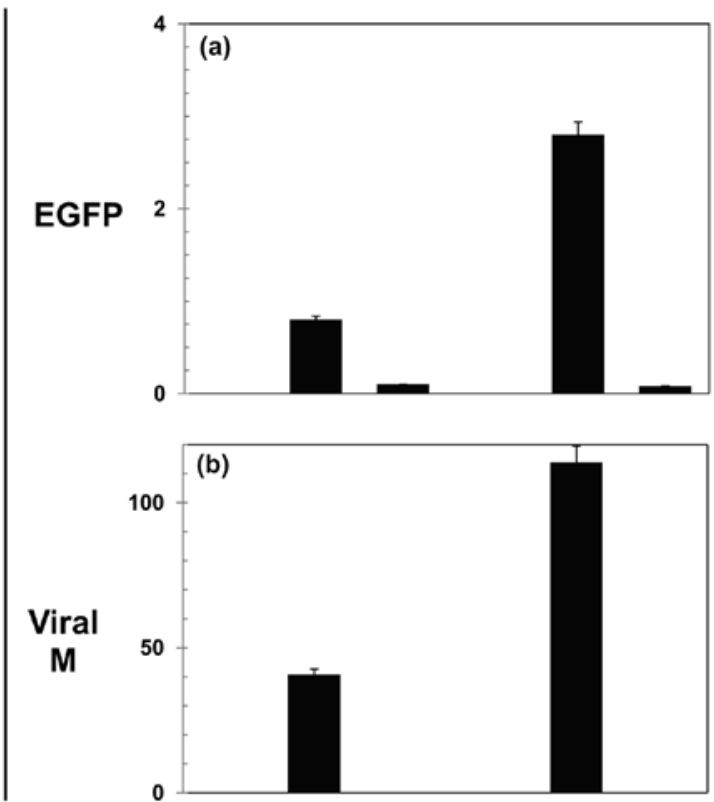

B)

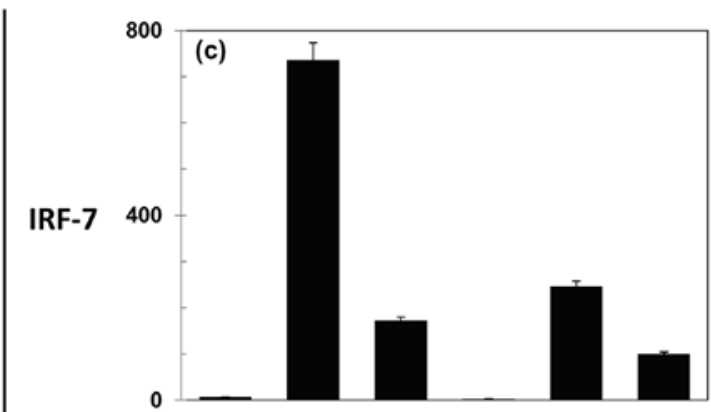

Interferon response
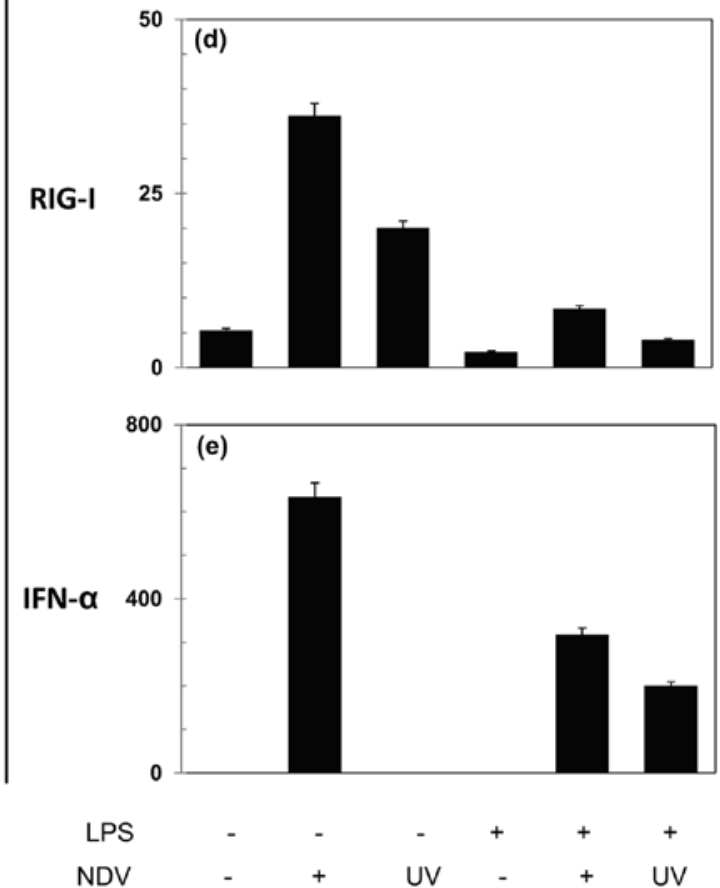

Figure 3. Effect of DC maturation and of UV irradiation of NDV on viral transcription (A) and on the type I interferon response induced in mouse BM-DCs (B) (A) Effect of DC maturation and UV irradiation of NDV on viral transcription. Mouse BM-DCs were either matured via a culture for $24 \mathrm{~h}$ with LPS (10 $\mu \mathrm{g} / \mathrm{ml})$ or not before being plated at $5 \times 10^{5}$ cells per well in a 24 -well plate. In some tests, NDV was UV-irradiated as described in Materials and methods. Recombinant NDFL-EGFP, which was UV-irradiated or not, was then given (30 HU NDFL-EGFP/10 6 cells) to each well and the cells were collected $24 \mathrm{~h}$ later and evaluated for viral replication by analyzing the EGFP fluorescence by flow cytometry (a) and by determining by quantitative PCR the amount of viral M transcripts (expressed in relative numbers) (b). The EGFP fluorescence is expressed as percentage of EGFP positive cells among the live cells as defined by propidium iodide staining. (B) Effect of DC maturation and UV-irradiation on the induced interferon response. Same conditions as in (A). The interferon response was analyzed by determining the levels of IRF-7 (c) or RIG-I (d) transcripts (expressed in relative numbers) by quantitative PCR (see Materials and methods) and evaluating the amount of IFN- $\alpha$ by ELISA (e). IFN- $\alpha$ is expressed in $\mathrm{pg} / \mathrm{ml}$. 
IFN- $\alpha$ (e) by quantitative PCR [for (c) and (d)] and ELISA [for (e)]. We observed that LPS maturation of dendritic cells leads to a weakening of the interferon response with a lower relative number of IRF-7 transcripts and also reduced IFN- $\alpha$ production. We conclude that maturation of DCs upon 24-h incubation with LPS leads to increased viral transcription but also to a weaker antiviral interferon response in vitro. To define the effect due to viral replication, we neutralized the capacity of NDV to replicate by UV-irradiation as described in Materials and methods. We observed that such UV-inactivated viruses were not able to replicate (Fig. 3A). Nevertheless they were able to induce an interferon response, albeit with a lower intensity (lower IRF-7 and RIG-I transcript levels and interferon- $\alpha$ concentrations).

Deletion of the genes coding for IRF-3, IRF-7 and IFNAR leads to higher transcription of NDV and to reduction of the DC cell viability. To determine which genes of the interferon pathway might be important for the control of viral replication, we generated in vitro BM-DCs derived from different $\mathrm{KO}$ mice (IRF-3KO, IRF-7KO, IRF-3 and IRF-7KO and IFNARKO). We then infected the cells with NDV (30 HU/10 $0^{6}$ cells) and analyzed viral $\mathrm{M}$ transcripts (Fig. 4A) $10.5 \mathrm{~h}$ (a) and $24 \mathrm{~h}$ (b) post-infection. We also tested BM-DCs to which LPS (at a final concentration of $30 \mathrm{ng} / \mathrm{ml}$ ) was given at the same time as NDV (Fig. 4Ac). We observed that the protein of the interferon-response transcription factor IRF-3, in contrast to the protein IRF-7, was important in the control of viral transcription since deletion of the IRF-3 gene led to increased levels of viral transcripts whereas deletion of IRF-7 did not. Deletion of both genes (IRF-3 and IRF-7) and also of the gene coding for the $\alpha$-chain of the type I interferon cell surface receptor (IFNAR) allowed higher transcription of viral genes. Analysis of cell viability after NDV infection of the BM-DC populations obtained from the different $\mathrm{KO}$ mice was measured in the MTS assay (Fig. 4B). Twenty-four hours post-infection, a direct relation was seen between the amounts of viral transcripts observed in Fig. 4A and the reduction of cell viability. Deletion of the genes coding for IRF-3 and IFNAR (but not for IRF-7) led to high transcription levels of the viral genes and to strong reduction of BM-DC viability.

Deletion of the IRF-3,IRF-7 andIFNAR geneleads to a decreased production of IRF-7 and RIG-I transcripts and of IFN- $\alpha$ and $T N F-\alpha$ cytokines upon NDV infection. Determination by quantitative PCR of the amounts of the IRF-7 and RIG-I transcripts which are induced upon NDV infection [but not upon addition of UV-NDV (data not shown)] showed a decrease in their number when one gene of the interferon pathway such as IRF-3, IRF-7 or both or IFNAR was deleted (Fig. 5A). Deletion of the IRF-3, IRF-7 or both genes simultaneously led also to a decrease of the levels of IFN- $\alpha$ (c), IFN- $\beta$ (d) and TNF- $\alpha$ (e) induced (Fig. 5B). The same was true for IFN- $\alpha$ (c) and TNF- $\alpha$ (e) upon deletion of the gene coding for IFNAR. However, deletion of the IFNAR gene, in contrast to deletion of the IRF-3 and IRF-7 genes, showed no diminution but an increase of the IFN- $\beta$ concentration (Fig. 5B). Very interestingly, addition of UV-NDV induced in wt DC higher levels of IRF-7 and RIG-I mRNAs but very low production of IFN- $\alpha$, IFN- $\beta$ and TNF- $\alpha$ in comparison to live NDV (data not shown).
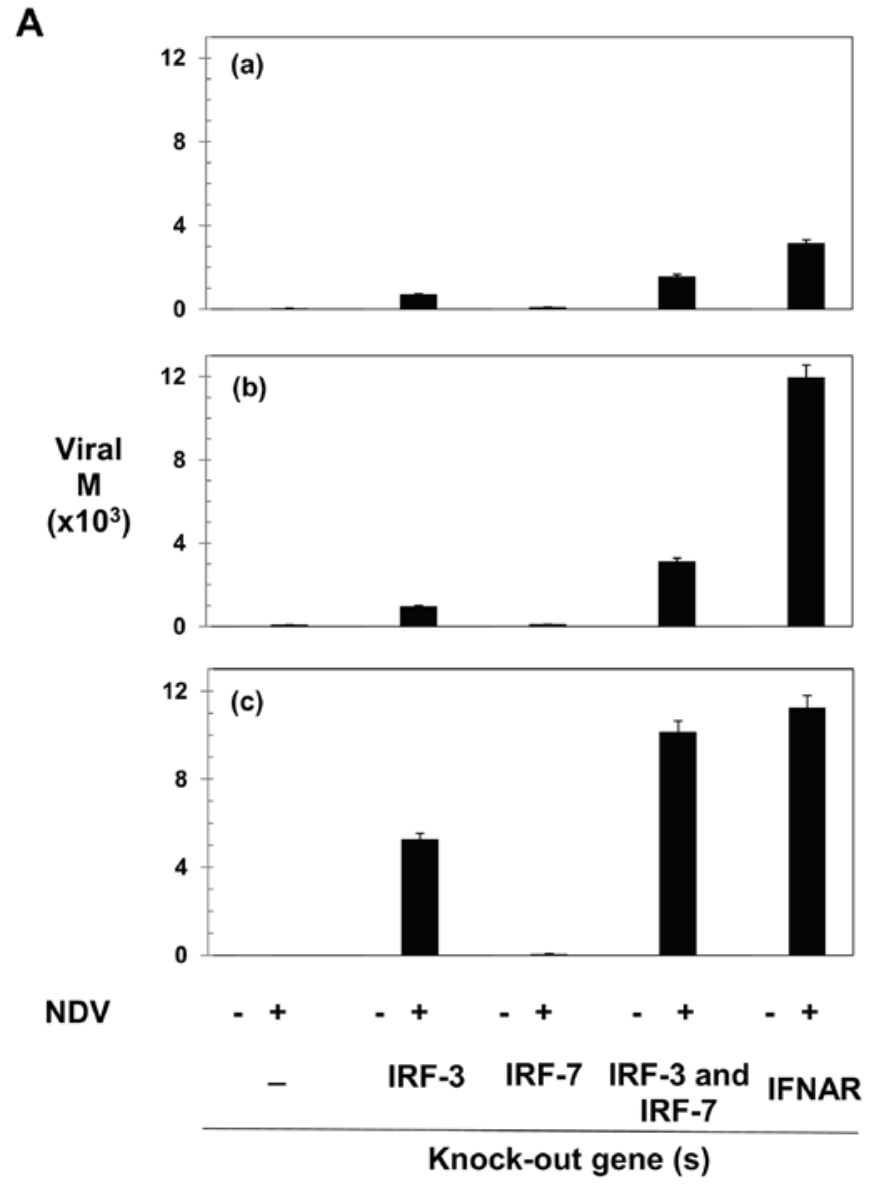

B

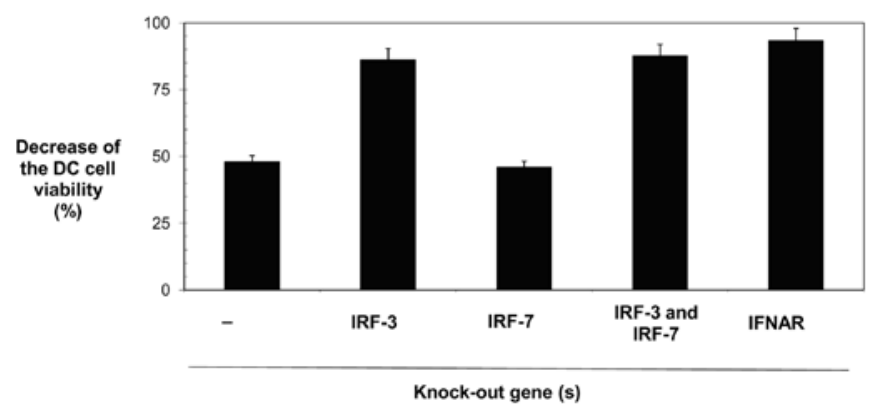

Figure 4. Levels of viral $M$ transcripts in BM derived dendritic cells which were obtained from WT, IRF-3KO, IRF-7KO, IRF-3+IRF-7KO and IFNARKO mice and which were infected by NDV Ulster (A) and decrease of cell viability after NDV addition (B). DCs were derived from different transgenic mice (IRF-3KO, IRF-7KO, IRF-3 and IRF-7KO, IFNARKO) as described in Materials and methods and were plated at $5 \times 10^{5}$ cells per well. In each well, $30 \mathrm{HU}$ of NDV Ulster or PBS (as control) was added [(a) and (b) respectively]. In (c), LPS was added to NDV Ulster at a final concentration of $30 \mathrm{ng} / \mathrm{ml}$. The cells were analyzed $10.5 \mathrm{~h}$ (a and c) or $24 \mathrm{~h}$ (b) later for the amount of viral M transcripts by quantitative PCR (A) and for their viability using the MTS assay at $24 \mathrm{~h}$ post-infection as described in Materials and methods (B).

Deletion of IFNAR but not of IRF-3 and IRF-7 genes leads to abolishment of IL-12 production by DC upon NDV/LPS treatment. Deletion of the IRF-3 or IRF-7 gene or both did not lead, upon NDV/LPS treatment, to impaired IL-12 production by BM-DCs despite the reduced interferon response (Fig. 6). Remarkably, deletion of the IFNAR gene led to the absence of RIG-I mRNA expression (Fig. 5A) and of IFN- $\alpha$ secretion (Fig. 5B) and also abolished the capacity for IL-12 production. We 
A)

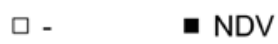

(a)

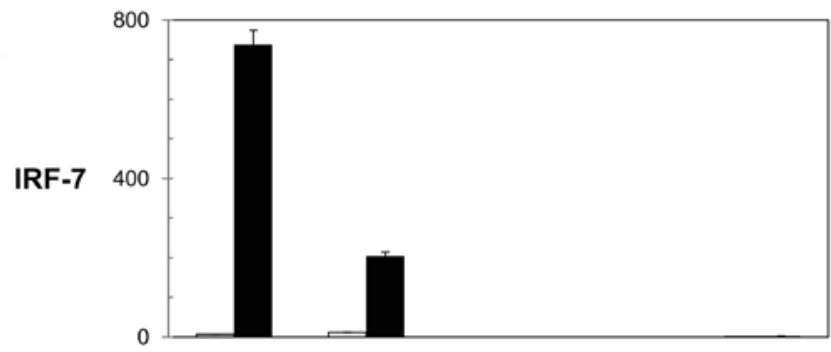

(b)

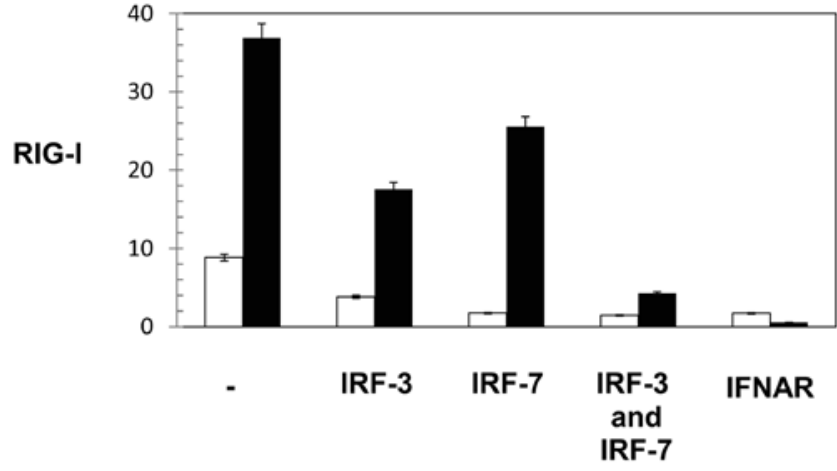

Knock-out gene (s)
B)
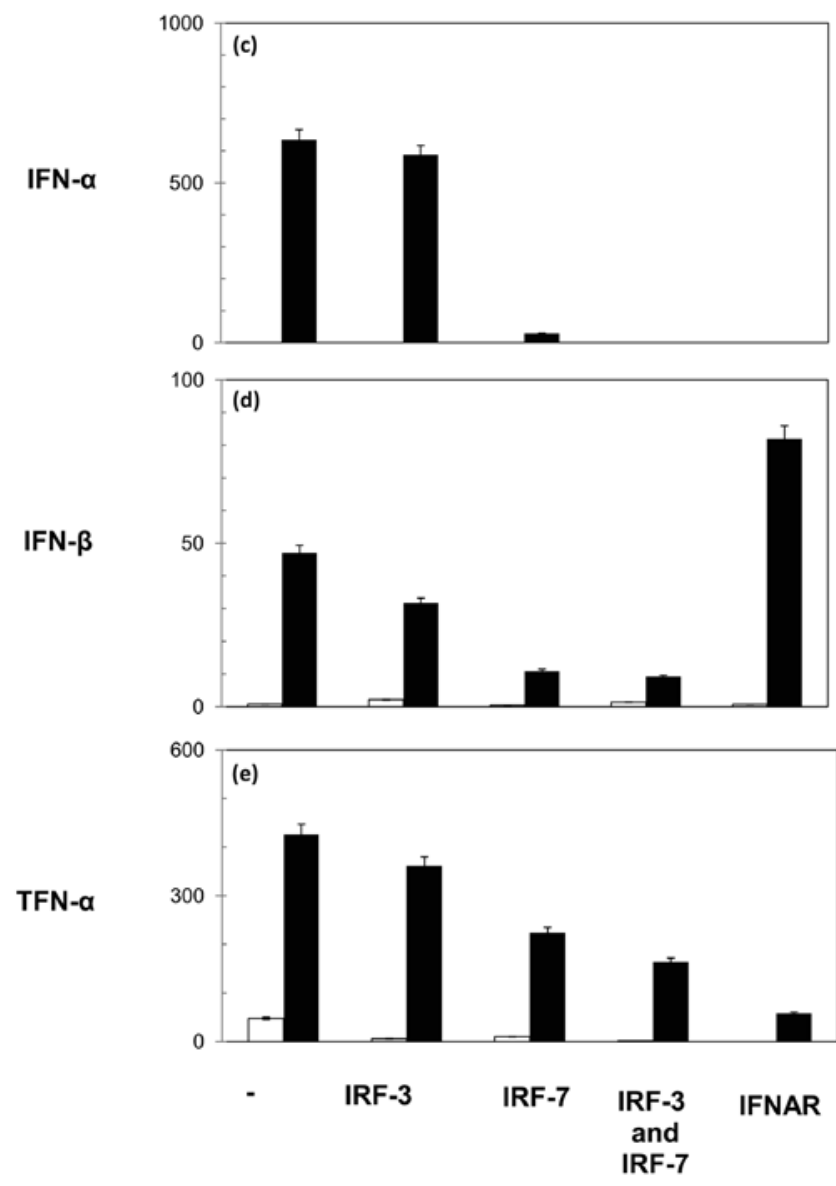

Knock-out gene (s)

Figure 5. Effects of the addition of NDV on the relative expression of IRF-3, IRF-7 and RIG-I transcripts in BM-DCs generated from wt, IRF-3KO, IRF-7KO, IRF-3+IRF-7KO and IFNARKO mice (A) and on the concentration of IFN- $\alpha$, IFN- $\beta$, TNF- $\alpha$ and IL-12 in the corresponding supernatants (B). BM-DC cells derived from the different KO mice were plated in 24-well plates $\left(5 \times 10^{5} /\right.$ well in 24 -well plates) and were either treated with PBS or NDV Ulster $\left(30 \mathrm{HU} / 10^{6}\right.$ cells). Ten and a half hours later, the cells were harvested in order to allow: (A) the evaluation of IRF-3 (a), IRF-7 (b) and RIG-I (c) transcripts by quantitative real-time PCR and (B) the determination of the concentration of IFN- $\alpha$ (c), IFN- $\beta$ (d) and TNF- $\alpha$ (e) by ELISA in the corresponding supernatants (B). All protein concentrations are given in $\mathrm{pg} / \mathrm{ml}$.

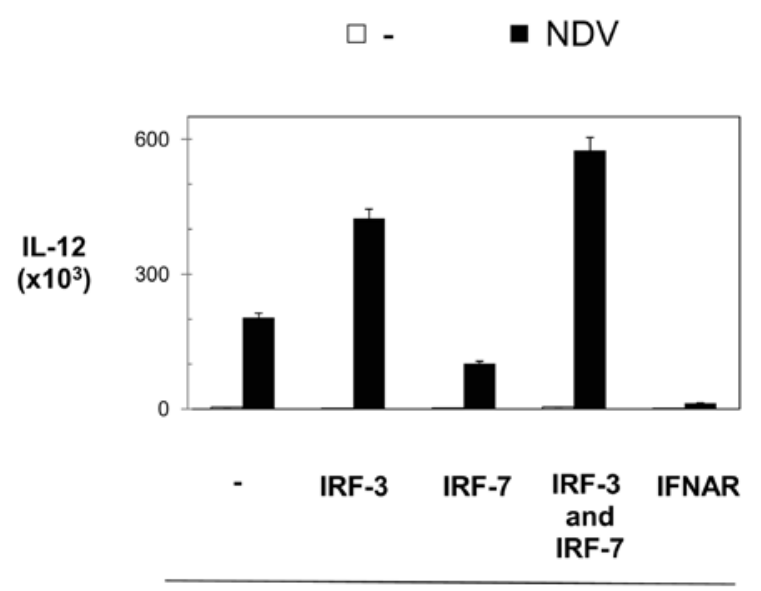

Knock-out gene (s)

Figure 6. Effects of the addition of NDV and UV-treated NDV on the concentrations of IL-12 in the supernatants of BM-DCs generated from wt, IRF-3KO, IRF-7KO, IRF-3+IRF-7KO and IFNARKO mice. Idem as in Fig. 5. The concentrations of IL-12 were determined by ELISA as indicated in Materials and methods and are given in $\mathrm{pg} / \mathrm{ml}$. conclude that RIG-I triggering in vitro through viral transcription in BM-DCs, leads to IL-12 production through a type 1 interferon receptor (but not IRF-3 and IRF-7) dependent pathway.

\section{Discussion}

In this study, we show that NDV induces in mice pro-inflammatory factors upon intranasal application. We also show that NDV can induce in human MDDCs the production of IL-6, IFN- $\alpha$, IL-10 and IL-12. The interferon response in these cells was linked to viral replication and was stronger in immature than in mature human MDDCs. In mouse BM-DCs, deletion of IRF-3 and IRF-7 genes led to higher transcription of the viral genes, to a decreased viability of the cells and to lower levels of the IFN- $\alpha$ and $-\beta$ transcripts. Finally, the knocking-out of the $\alpha$ chain of the IFN receptor gene totally abolished the capacity of the DC to produce IFN- $\alpha$ and IL-12 proteins, but not the production of IFN- $\beta$. These results highlight the key role played by the IFNAR pathway in the induction of IL-12 upon trig- 


\section{In privileged sites (such as the bone marrow)}

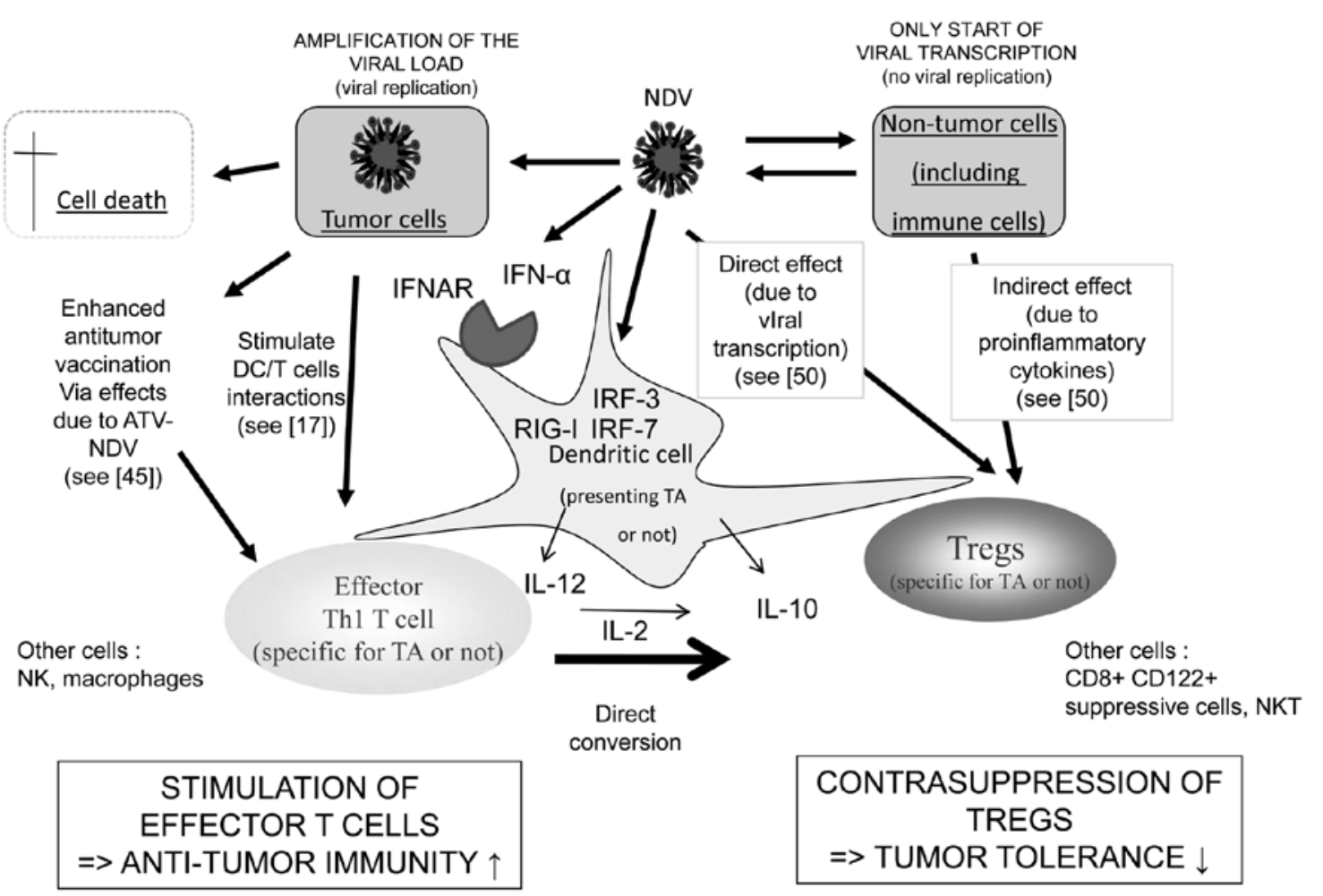

Figure 7. Overview of the proposed mechanism of stimulation of Teff cells and suppression of Tregs by NDV (see Discussion for more details).

gering BM-DCs with bacterial (LPS) and viral (dsRNA) danger signal inducing compounds. It is also of great interest that only a concerted activation of a Toll-like receptor in the membrane of DCs (i.e., TLR-4) and of a cytoplasmic receptor (RIG-I) evoked the production of IL-12 which is very important for a Th1 type T cell response.

These observations are important given the evidence that supports the concept that the host immune system interacts with the developing tumor and can play a role in the arrest of tumor growth in experimental animals and in man (38). In these interactions referred to as 'immunosurveillance', the dendritic cells play a crucial role. DCs are the most potent antigen-presenting cells and acquire cellular antigens and danger signals from dying cells to initiate antitumor immune responses via direct cell-to-cell interaction and cytokine production. The kind of tumor cell death appears critical for priming DCs via the release of danger signals. The microenvironmental milieu and the context in which an antigen is presented to the immune system appear as extremely important for the type of $\mathrm{T}$ cell response and its regulation (39). And the DCs must be activated adequately to be capable of priming naive $\mathrm{T}$ cells or re-stimulating memory $\mathrm{T}$ cells, especially in an immunosuppressive microenvironment. To this end, virus-mediated DC triggering might be an effective means for immature DCs to induce specific $\mathrm{T}$ cell reactivity against human cancer cells.

This is important for tumor therapy based on the use of NDV, in particular because of the plasticity of Teff and Treg populations. Recent discoveries indicating how micro-environmental cytokines refine/modify Treg phenotype and function, thus changing their fate, might help to explain the strong antitumor activity of NDV making this virus an attractive anti-cancer agent.

NDV was shown to augment anti-tumor T cell immunity upon infection of tumor cells (reviewed in ref. 17). But it has also been observed to direct DCs towards a DC1 phenotype (36) and to stimulate DC-T cell interactions (40). Viral nucleic acids are described as potent activators of innate immunity leading to the secretion of cytokines. In this study, we observed the induction by NDV of pro-inflammatory cytokines and we analyzed in more detail the type I IFN response.

Antigen-presenting mature DCs can prime naive $\mathrm{T}$ cells while immature DCs induce deletion or anergy of antigen-reactive T cells or induce antigen-specific Tregs (41-43). Treg cells play a central role in the suppression of immune reactions and in the prevention of autoimmune responses harmful to the host $(44,45)$. In particular, Treg cells suppress the activation of naive effector T (Teff) cells by inhibiting TCR-triggered proliferation and differentiation of these cells (46).

In recent years, bacterial components have been shown to have an effect on Treg activity. The production of inflammatory cytokines by bacterial molecules such as LPS or CpG DNA can render effector $\mathrm{T}$ cells resistant to suppression by Tregs (47). Other bacterial components such as the flagellin have been shown to lead to Treg activation and enhancement of their suppressive function (48). In contrast, transfer of supernatants from DCs stimulated with inactivated Sendai Virus particles could reduce suppressive function of Tregs (49), indicating that viruses could also indirectly inhibit the function of Treg cells. Recently, immunostimulatory RNA was demonstrated to block suppression by Tregs using synthetic RNA oligonucleotides 
and the RNA viruses such as encephalomyocarditis virus and Sendai virus. Anz et al (50) showed that the activation of the RIG-I helicase in Treg cells blocks the suppressive functions of these cells. These authors demonstrated in an APC-independent system that direct stimulation of the RIG-I helicases in Treg cells is necessary to inhibit their suppressive function upon viral infection. In addition, simultaneous activation of MDA-5 in Teff cells is required for this inhibition, suggesting interactions between Teff and Treg during the blocking of the Treg cellinduced suppression. More recently, Hoechst et al (51) reported that human CD14(+)HLA-DR(-/low) myeloid derived suppressor cells (MDSC) induce Foxp3(+) regulatory $\mathrm{T}$ cells, whereas CD14(+)HLA-DR(+) monocytes promote generation of IL-17 secreting, ROR $\gamma(+)$ Th17 cells when co-cultured with naive CD4(+) T cells. The authors of this study also showed that these two CD14+ subsets do not only modulate the de novo induction of Tregs and Th17 cells from CD4(+) T cells, but MDSC also catalyze the trans-differentiation of Foxp3(+) regulatory $\mathrm{T}$ cells from monocyte-induced Th17 cells.

Interferon- $\alpha$ has been shown to suppress the generation of activated Tregs while simultaneously promoting the generation of CD4 Teffs $(52,53)$. The associated mechanism would imply interleukin (IL)-2 production in which a transient production of IFN- $\alpha$ has been proposed to promote functions of CD4 Teff cells. This would delay activated Treg generation. A chronic elevation of IFN- $\alpha$ may then favor activated Teffs and autoimmunity. Both, inflammatory factors and IFN- $\alpha$, appear to have the potential to counteract Treg activity.

In this respect, it is of interest to note that BM has been described as a unique organ in which CD8 memory $\mathrm{T}$ cells undergo vigorous homeostatic proliferation and respond faster to antigen stimulation than other tissues $(54,55)$. It actively accumulates CD8 central memory T cells. These are more frequent in the BM than elsewhere (56). In cancer patients, memory $\mathrm{T}$ cells in the $\mathrm{BM}$ have greater antitumor reactivity than do peripheral blood derived memory T cells (57). In addition, BM has been described as an organ important for T cell-priming (58). We demonstrated that naive, antigen-specific T cells home to BM, where they can be primed by resident $\mathrm{CD} 11 \mathrm{c}^{+}$dendritic cells. This occurs via dendritic cell-T cell clustering in BM stroma. The resulting responses are not tolerogenic and result in the generation of cytotoxic T cells with protective anti-tumor immunity and immunological memory (59).

We propose that NDV can orchestrate the conversion of naive CD4(+) T cells into Teff cells and shut off the generation of Treg cells. Teff and Treg cells have opposite impacts on immune responses to tumors. NDV might ensure that immune reactions change from tolerance to antitumor reactivity (Fig. 7).

Taken together, NDV appears as a vector with a great potential for the treatment of cancer. It appears to play a crucial role in immune regulation. We propose here that NDV can be used to diminish tolerance development and to enhance anti-tumor immunity.

\section{Acknowledgements}

We thank DrBen Peeters from the Division of Infectious Diseases, Animal Sciences Group, Wageningen UR, AB Lelystad, The Netherlands for the recombinant EGFP-expressing NDV. We also acknowledge the kindness of Professor Rainer Zawatzky (Division of Viral Transformation Mechanisms, German Cancer Research Center, Heidelberg, Germany) for providing IFNAR ${ }^{-/-}$ mice. We thank Anne Krug from the Department of Internal Medicine II, Klinikum Rechts der Isar, Technical University Munich, Germany for providing us the IRF-3, IRF-7 and the double IRF-3/IRF-7 knocked-out mice. We thank the IOZK Köln (http://www.iozk.de) for financial support to help defray the costs of publication.

\section{References}

1. Banchereau J, Briere F, Caux C, Davoust J, Lebecque S, Liu YJ, Pulendran B and Palucka K: Immunobiology of dendritic cells. Annu Rev Immunol 18: 767-811, 2000.

2. Arima K, Watanabe N, Hanabuchi S, Chang M, Sun SC and Liu YJ: Distinct signal codes generate dendritic cell functional plasticity. Sci Signal 3: ra4, 2010.

3. Pullarkat V, Lau R, Lee SM, Bender JG and Weber JS: Largescale monocyte enrichment coupled with a closed culture system for the generation of human dendritic cells. J Immunol Methods 267: 173-183, 2002.

4. Nestle FO, Alijagic S, Gilliet M, Sun Y, Grabbe S, Dummer R, Burg G and Schadendorf D: Vaccination of melanoma patients with peptide- or tumor lysate-pulsed dendritic cells. Nat Med 4: 328-332, 1998.

5. Hsu FJ, Benike C, Fagnoni F, Liles TM, Czerwinski D, Taidi B, Engleman EG and Levy R: Vaccination of patients with B-cell lymphoma using autologous antigen-pulsed dendritic cells. Nat Med 2: 52-58, 1996.

6. Rosenberg SA, Yang JC and Restifo NP: Cancer immunotherapy: moving beyond current vaccines. Nat Med 10: 909-915, 2004.

7. Curiel TJ, Coukos G, Zou L, Alvarez X, Cheng P, Mottram P, Evdemon-Hogan M, Conejo-Garcia JR, Zhang L, Burow M, Zhu Y, Wei S, Kryczek I, Daniel B, Gordon A, Myers L, Lackner A, Disis ML, Knutson KL, Chen L and Zou W: Specific recruitment of regulatory $\mathrm{T}$ cells in ovarian carcinoma fosters immune privilege and predicts reduced survival. Nat Med 10: 942-949, 2004.

8. Strauss L, Bergmann C and Szczepanski M: A unique subset of $\mathrm{CD}^{+} \mathrm{CD} 25$ highFoxp $3^{+} \mathrm{T}$ cells secreting interleukin-10 and transforming growth factor-beta1 mediates suppression in the tumor microenvironment. Clin Cancer Res 13: 4345-4354, 2007.

9. Timmerman JM and Levy R: Dendritic cell vaccines for cancer immunotherapy. Annu Rev Med 50: 507-529, 1999.

10. Cerundolo V, Hermans IF and Salio M: Dendritic cells: a journey from laboratory to clinic. Nat Immunol 5: 7-10, 2004.

11. Saito T and Gale M Jr: Differential recognition of doublestranded RNA by RIG-I-like receptors in antiviral immunity. $\mathrm{J}$ Exp Med 205: 1523-1527, 2008.

12. Pichlmair A and Reis e Sousa C: Innate recognition of viruses. Immunity 27: 370-383, 2007.

13. Akira S, Uematsu S and Takeuchi O: Pathogen recognition and innate immunity. Cell 124: 783-801, 2006.

14. Banchereau J and Palucka AK: Dendritic cells as therapeutic vaccines against cancer. Nat Rev Immunol 5: 296-306, 2005.

15. Takeuchi O and Akira S: Recognition of viruses by innate immunity. Immunol Rev 220: 214-224, 2007.

16. Endo Y, Sakai R, Ouchi M, Onimatsu H, Hioki M, Kagawa S, Uno F, Watanabe Y, Urata Y, Tanaka N and Fujiwara T: Virusmediated oncolysis induces danger signal and stimulates cytotoxic T-lymphocyte activity via proteasome activator upregulation. Oncogene 27: 2375-2381, 2008.

17. Schirrmacher V and Fournier P: Newcastle disease virus: a promising vector for viral therapy, immune therapy, and gene therapy of cancer. Methods Mol Biol 542: 565-605, 2009.

18. Kato H, Sato S, Yoneyama M, Yamamoto M, Uematsu S, Matsui K, Tsujimura T, Takeda K, Fujita T, Takeuchi O and Akira S: Cell type-specific involvement of RIG-I in antiviral response. Immunity 23: 19-28, 2005.

19. Stetson DB and Medzhitov R: Antiviral defense: interferons and beyond. J Exp Med 203: 1837-1841, 2006.

20. Kato H, Takeuchi O, Sato S, Yoneyama M, Yamamoto M, Matsui K, Uematsu S, Jung A, Kawai T, Ishii KJ, Yamaguchi O, Otsu K, Tsujimura T, Koh CS, Reis e Sousa C, Matsuura Y, Fujita T and Akira S: Differential roles of MDA5 and RIG-I helicases in the recognition of RNA viruses. Nature 441: 101-105, 2006. 
21. Loo YM, Fornek J, Crochet N, Bajwa G, Perwitasari O, MartinezSobrido L, Akira S, Gill MA, García-Sastre A, Katze MG and Gale M Jr: Distinct RIG-I and MDA5 signaling by RNA viruses in innate immunity. J Virol 82: 335-345, 2008.

22. Gitlin L, Barchet W, Gilfillan S, Cella M, Beutler B, Flavell RA Diamond MS and Colonna M: Essential role of mda-5 in type I IFN responses to polyriboinosinic:polyribocytidylic acid and encephalomyocarditis picornavirus. Proc Natl Acad Sci USA 103: 8459-8464, 2006.

23. Sinkovics JG and Horvath JC: Newcastle disease virus (NDV): brief history of its oncolytic strains. J Clin Virol 16: 1-15, 2000.

24. Fiola C, Peeters B, Fournier P, Arnold A, Bucur M and Schirrmacher V: Tumor selective replication of Newcastle disease virus: association with defects of tumor cells in antiviral defence. Int J Cancer 119: 328-338, 2006.

25. Wilden H,Fournier P,Zawatzky R and Schirrmacher V: Expression of RIG-I, IRF-3, IFN-beta and IRF-7 determines resistance or susceptibility of cells to infection by Newcastle disease virus. Int J Oncol 34: 971-982, 2009.

26. Stetson DB and Medzhitov R: Type I interferons in host defense Immunity 25: 373-381, 2006 .

27. Colonna M, Trinchieri G and Liu YJ: Plasmacytoid dendritic cells in immunity. Nat Immunol 5: 1219-1226, 2004

28. Lorence RM, Roberts MS, Groene WS and Rabin H: Replicationcompetent, oncolytic Newcastle Disease Virus for cancer therapy. In: Replication-Competent Viruses for Cancer Therapy. Vol. 22. Hernáiz Driever P and Rabkin SD (eds). Monogr Virol, Karger, Basel, pp160-182, 2001.

29. Peeters BP, De Leeuw OS, Koch G and Gielkens AL: Rescue of Newcastle disease virus from cloned cDNA: evidence that cleavability of the fusion protein is a major determinant for virulence. J Virol 73: 5001-5009, 1999.

30. Zhao H, Janke M, Fournier P and Schirrmacher V: Recombinant Newcastle disease virus expressing human interleukin-2 serves as a potential candidate for tumor therapy. Virus Res 136: 75-80, 2008.

31. Janke M, Peeters B, Zhao H, de Leeuw O, Moorman R, Arnold A, Ziouta Y, Fournier P and Schirrmacher V: Activation of human $\mathrm{T}$ cells by a tumor vaccine infected with recombinant Newcastle disease virus producing IL-2. Int J Oncol 33: 823-832, 2008

32. Janke M,Peeters B, De Leeuw O, Moorman R, Arnold A,Fournier P and Schirrmacher V: Recombinant Newcastle disease virus (NDV) with inserted gene coding for GM-CSF as a new vector for cancer immunogene therapy. Gene Ther 14: 1639-1649, 2007.

33. Macatonia SE, Hosken NA, Litton M, Vieira P, Hsieh CS Culpepper JA, Wysocka M, Trinchieri G, Murphy KM and O'Garra A: Dendritic cells produce IL-12 and direct the development of Th1 cells from naive CD $4^{+} \mathrm{T}$ cells. J Immunol 154 5071-5079, 1995

34. Cella M, Scheidegger D, Palmer-Lehmann K, Lane P, Lanzavecchia A and Alber G: Ligation of CD40 on dendritic cells triggers production of high levels of interleukin-12 and enhances T cell stimulatory capacity: T-T help via APC activation. J Exp Med 184: 747-752, 1996.

35. Fournier P, Arnold A and Schirrmacher V: Polarization of human monocyte-derived dendritic cells to $\mathrm{DC} 1$ by in vitro stimulation with Newcastle Disease Virus. J BUON 1 (Suppl.): S111-S122, 2009.

36. Al-Garib SO, Gielkens AL, Gruys E, Peeters BP and Koch G: Tissue tropism in the chicken embryo of non-virulent and virulent Newcastle diseases strains that express green fluorescence protein. Avian Pathol 32: 591-596, 2003.

37. Schirrmacher V, Haas C, Bonifer R, Ahlert T, Gerhards R and Ertel C: Human tumor cell modification by virus infection: an efficient and safe way to produce cancer vaccine with pleiotropic immune stimulatory properties when using Newcastle disease virus. Gene Ther 6: 63-73, 1999.

38. Whiteside TL: Immune responses to malignancies. J Allergy Clin Immunol 125 (Suppl. 2): 272-283, 2010.

39. Schuler G and Steinman RM: Dendritic cells as adjuvants for immune-mediated resistance to tumors. J Exp Med 186: 1183-1187, 1997.

40. Bai L, Koopmann J, Fiola C, Fournier P and Schirrmacher V: Dendritic cells pulsed with viral oncolysates potently stimulate autologous T cells from cancer patients. Int J Oncol 21: 685-694, 2002.
41. Mahnke K, Schmitt E, Bonifaz L, Enk AH and Jonuleit $\mathrm{H}$ : Immature, but not inactive: the tolerogenic function of immature dendritic cells. Immunol Cell Biol 80: 477-483, 2002.

42. Probst HC, Lagnel J, Kollias G and van den Broek M: Inducible transgenic mice reveal resting dendritic cells as potent inducers of $\mathrm{CD}^{+} \mathrm{T}$ cell tolerance. Immunity 18: 713-720, 2003

43. Hawiger D, Inaba K, Dorsett Y, Guo M, Mahnke K, Rivera M, Ravetch JV, Steinman RM and Nussenzweig MC: Dendritic cells induce peripheral $\mathrm{T}$ cell unresponsiveness under steady state conditions in vivo. J Exp Med 194: 769-779, 2001.

44. Bluestone JA and Tang Q: How do $\mathrm{CD} 4^{+} \mathrm{CD} 25^{+}$regulatory T cells control autoimmunity? Curr Opin Immunol 17: 638-642, 2005.

45. Sakaguchi S and Powrie F: Emerging challenges in regulatory $\mathrm{T}$ cell function and biology. Science 317: 627-629, 2007.

46. Von Boehmer H: Mechanisms of suppression by suppressor $\mathrm{T}$ cells. Nat Immunol 6: 338-344, 2005.

47. Kubo T, Hatton RD, Oliver J, Liu X, Elson CO and Weaver CT: Regulatory $\mathrm{T}$ cell suppression and anergy are differentially regulated by proinflammatory cytokines produced by TLR-activated dendritic cells. J Immunol 173: 7249-7258, 2004.

48. Crellin NK, Garcia RV, Hadisfar O, Allan SE, Steiner TS and Levings MK: Human CD4 ${ }^{+} \mathrm{T}$ cells express TLR5 and its ligand flagellin enhances the suppressive capacity and expression of FOXP3 in $\mathrm{CD} 4{ }^{+} \mathrm{CD} 25^{+} \mathrm{T}$ regulatory cells. J Immunol 2175 : 8051-8059, 2005

49. Kurooka M and Kaneda Y: Inactivated Sendai virus particles eradicate tumors by inducing immune responses through blocking regulatory T cells. Cancer Res 67: 227-236, 2007.

50. Anz D, Koelzer VH, Moder S, Thaler R, Schwerd T, Lahl K, Sparwasser T, Besch R, Poeck H, Hornung V, Hartmann G, Rothenfusser S, Bourquin C and Endres S: Immunostimulatory RNA blocks suppression by regulatory T cells. J Immunol 184: 939-946, 2010

51. Hoechst B, Gamrekelashvili J, Manns MP, Greten TF and Korangy F: Plasticity of human Th17 cells and iTregs is orchestrated by different subsets of myeloid cells. Blood 117: 6532-6541, 2011

52. Gigante M, Mandic M, Wesa AK, Cavalcanti E, Dambrosio M, Mancini V, Battaglia M, Gesualdo L, Storkus WJ and Ranieri E: Interferon-alpha (IFN- $\alpha$ )-conditioned DC preferentially stimulate type-1 and limit Treg-type in vitro T-cell responses from RCC patients. J Immunother 31: 254-262, 2008

53. Golding A, Rosen A, Petri M, Akhter E and Andrade F: Interferonalpha regulates the dynamic balance between human activated regulatory and effector $T$ cells: implications for antiviral and autoimmune responses. Immunology 131: 107-117, 2010.

54. Di Rosa F and Santoni A: Bone marrow CD8 T cells are in a different activation state than those in lymphoid periphery. Eur J Immunol 32: 1873-1880, 2002.

55. Becker TC, Coley SM, Wherry EJ and Ahmed R: Bone marrow is a preferred site for homeostatic proliferation of memory CD8 T cells. J Immunol 174: 1269-1273, 2005.

56. Mazo IB, Honczarenko M, Leung H, Cavanagh LL, Bonasio R, Weninger W, Engelke K, Xia L, McEver RP, Koni PA, Silberstein LE and von Andrian UH: Bone marrow is a major reservoir and site of recruitment for central memory $\mathrm{CD}^{+} \mathrm{T}$ cells. Immunity 22 : 259-270, 2005

57. Feuerer M, Beckhove P, Bai L, Solomayer EF, Bastert G, Diel IJ, Pedain C, Oberniedermayr M, Schirrmacher V and Umansky V: Therapy of human tumors in NOD/SCID mice with patientderived reactivated memory $\mathrm{T}$ cells from bone marrow. Nat Med 7: 452-458, 2001

58. Feuerer M, Beckhove P, Garbi N, Mahnke Y, Limmer A, Hommel M, Hämmerling GJ, Kyewski B, Hamann A, Umansky V and Schirrmacher V: Bone marrow as a priming site for T-cell responses to blood-borne antigen. Nat Med 9: 1151-1157, 2003.

59. Schirrmacher V, Feuerer M, Fournier P, Ahlert T, Umansky V and Beckhove P: T-cell priming in bone marrow: the potential for long-lasting protective anti-tumor immunity. Trends Mol Med 9: 526-534, 2003. 